\title{
THE PROTECTIVE ROLE OF ASCORBIC ACID (VITAMIN C) ON NEUROTOXICITY OF DELTAMETHRIN ON THE SCIATIC NERVE OF ALBINO RAT
}

By

Mohamed E.A. Mostafa

Anatomy Department, Faculty of Medicine, Cairo University

\section{INTRODUCTION}

Synthetic pyrethroid insecticides had been widely used (in agriculture, home pest control and disease vector control) for their high activity as an insecticide and low mammalian toxicity. This low mammalian toxicity was due, in part, to their rapid metabolism in these animals (Dick et al., 1984). Pyrethroids had been subdivided into two classes based on their structural characteristics and pharmacological effects. Type I pyrethroids such as allethrin and permethrin do not contain $\alpha$-cyano group, which is present in type II pyrethroids such as deltamethrin, cypermethrin and fenvalerate (Moya-Quiles et al., 1996). The lipophilia of pyrethroids favored their absorption through the skin, gastrointestinal and respiratory tracts to be more distributed into lipid-rich internal tissues, including body fat and elements of the central and peripheral nervous system (Soderlund et al., 2002).

However, it has been proved that pyrethroids were toxic to the central nervous system of both insects and mammals, as transient paraesthesia which occured with skin contact with type I pyrethroids (Husain et al., 1994). On the other hand muscle fasciculations, choreoathetosis, salivation and convulsions which might lead to death were associated with systemic poisoning following ingestion of type 11 pyrethroids (Ecobichon, 1995). Husain et al., (1996) owed the central effect of deltamethrin to dendritic degeneration of Purkinje neurons of the cerebellar region of rats. Meanwhile, Dick et al. (1984) found no affection on the peripheral nerves. They reported that there were no changes in sural and tibial nerves and in the maxillary division of cranial nerve $V$ of rats fed with permethrin for long periods. However, peripheral nerve damage was described in rats intoxicated with high doses of permethrin (Cavaliere et al., 1990). Studies of the toxicity of pyrethroid insecticides in the central and peripheral nervous system of mammals were generally concerned with the biochemical, pharmacological and physiological effects of these products. Morphological studies were scarce and there were few studies with detailed histological description of nerve lesions caused by deltamethrin (Calore et al., 2000).

Joy (1994) reported that deltamethrin caused a persistent depolarization and frequency-dependent conduction block in sensorial and motor ax- 
ons as well as prolonged repetitive firing of sensorial ends and muscle fibers. Also, Husain et al. (1996) found that monoamine oxidase activity increased and $\mathrm{Na}^{+}, \mathrm{K}^{+}$- ATPase activity decreased in various regions of the CNS in rats intoxicated with the deltamethrin. Moreover, Aziz et al. (2001) explained its interaction with the $y$-aminobutyric acid (GABA) receptorionophore complex resulting in disturbed synaptic transmission and neuroexcitation, which in turn lead to behavioral anomalies. Furthermore, Braguini et al. (2004) added that its primary target was the neuronal voltage-dependent sodium channel.

L-ascorbic acid (Vitamin C) is an important antioxidant with multiple antioxidant properties. Its water solubility allows it to be widely distributed in both the extracellular and intracellular spaces in most biological systems (Jha et al., 1995). In addition, vitamin C suppressed the inactivation of antiproteases by oxidants generated from the neutrophil myeloperoxidase halide system, of stimulated neutrophils, in inflammatory conditions. This was performed through a dose-dependent neutralization of extracellular oxidants released from those neutrophils (Theron and Andersen, 1985). Vitamin $\mathrm{C}$ was also capable of maintaining sulfhydryl compounds in a reduced state, participating in many redox reactions and scavenging singlet oxygen and free radicals (Bendich et al., 1986). Moreover, Frei and Loginove (1998) indicated that in plasma, ascorbate was the most effective scavenger of aqueous peroxyl radicals. It was not only capable of completely protecting the lipids against detectable peroxidative damage but also spared $\alpha$ - tocopherol, which is a strong membrane stabilizer, thus preserving the membranes. Furthermore, Slater (1984) demonstrated that vitamin $C$ contributs to the regeneration of the membranes.

The rat was the experimental model of choice for many investigations of peripheral nerve injury as, excluding size and connective tissue density, the rat nerve was fundamentally indistinguishable from that of man (Mackinnon et al., 1985).

The aim of the present work was to study the histological changes of the sciatic nerve of rats intoxicated with deltamethrin. It was also aimed to detect the possible protective effect of vitamin $\mathrm{C}$ when given concomitantly with deltamethrin.

\section{MATERIAL AND METHODS}

\section{Animals and drugs}

This study was carried out on 80 male adult albino rats, weighing 200$250 \mathrm{~g}$. They were obtained from the Animal house, Faculty of Medicine, Cairo University, kept there in metal cages where food and water were given ad libitum throughout the study. They were divided into six groups: 
1. Group 1 (normal control group), 20 rats, received no medication.

2. Group 2 (sham control group), 20 rats, was divided into two equal subgroups: subgroup 2a received ascorbic acid and subgroup $2 b$ received corn oil.

3. Group 3 (deltamethrin treated group), ten rats, received deltamethrin.

4. Group 4 (ascorbic acid and deltamethrin treated group), ten rats, received deltamethrin and ascorbic acid.

5. Group 5 (deltamethrin withdrawal group), ten rats, received deltamethrin.

6. Group 6 (ascorbic acid and deltamethrin withdrawal group), ten rats, re ceived deltamethrin and ascorbic acid.

Corn oil was given in a daily dose of $1 \mathrm{~mL}$ by oral gavage for three days started in the first day of deltamethrin administration. Deltamethrin was obtained from National Organization for Drug Control and Research in Cairo and was given in a daily dose of $45 \mathrm{mg} / \mathrm{kg}$ dissolved in $1 \mathrm{~mL}$ corn oil by oral gavage for three days according to Calore et al. (2000). Ascorbic acid was given in a daily dose of $4 \mathrm{~mL}$ of $5 \%$ ascorbic acid in water (divided into two doses) for six days started three days before deltamethrin administration according to Kaviraj (2003). The animals of groups $3 \& 4$ were sacrificed in the $4^{\text {th }}$ day of deltamethrin administration while, the animals of groups $5 \& 6$ were sacrificed ten days after deltamethrin cessation. Half of the control groups were used as control for groups $3 \& 4$, while the other half were used as control for groups $5 \& 6$. Scarification was done by decapitation. The sciatic nerve of each animal was subjected to light microscopic examination using osmic acid and toluidine blue stains and also electron microscopic examination was performed.

\section{Procedure}

Sciatic nerve was dissected and divided into two fragments. One fragment of each nerve was washed through two changes of distilled water for five minutes each, placed in $0.05 \%$ osmic acid solution for 24 hours, then washed in the running tap water, dehydrated and embedded in paraffin. Transverse sections of $5 \mu \mathrm{m}$-thickness were cut and examined by light microscopy according to Johnson (1997). The other fragment was fixed in fresh $3 \%$ glutaraldehyde at $4^{\circ} \mathrm{C}$ for four hours, washed in $0.15 \mathrm{M}$ phosphate buffer, $\mathrm{pH} 7.4$, for two hours (two changes), postfixed in $1 \%$ osmium tetroxide for one hour at $4^{\circ} \mathrm{C}$, dehydrated and embedded in epoxy resin. Serial semithin sections were cut at $1 \mu \mathrm{m}$-thickness by Seo UMTP-6M ultramicrotome, stained with $1 \%$ toluidine blue and examined by Zeiss Axiophot microscope. For electron microscopy, ultrathin sections $(0.1 \mu \mathrm{m}$ thick) were prepared using the same ultramicrotome and stained with uranyl acetate and lead citrate according to Chen et al. (2001). The sections were examined by Seo TEM and photographed under different magnifications. 


\section{Gross Observations}

\section{RESULTS}

Rats treated with deltamethrin groups (3-6) exhibited clinical signs of acute intoxication including salivation, hyperactivity, incoordination, coarse seizures and tremors from the first day of treatment. These symptoms became progressively improved in groups $5 a n d 6$ after deltamethrin cessation.

\section{Light Microscopy}

Examination of the sciatic nerve of groups 1 and2 revealed the normal structure of the sciatic nerve. The nerve fibers were present in fascicles surrounded with perineurium and epineurium sheathes and their myelin sheath was surrounded by endoneurium (Fig .1). Each fascicle contained a large number of myelinated and some nonmyelinated nerve fibers which were small to large in diameter (Figs.2, 3). Few small blood vessels were observed (Figs. 1, 3).

After deltamethrin administration (group 3), there was obvious increase in C.T. endoneurium in some fascicles with marked decrease in number of myelinated nerve fibers, many of them were swollen with disrupted axoplasm and myelin fragments inside (Wallerian degeneration), while the nonmyelinated nerve fibers appeared nonaffected (Fig.4), in other fascicles there was no obvious increase in endoneurium however, most of the myelinated nerve fibers showed Wallerian degeneration (Fig.5).

Administration of ascorbic acid with deltamethrin (group 4) had minimized the effect of deltamethrin on nerve fibers. Some fibers showed Wallerian degeneration, others were regenerating, while few showed normal structure. The regeneration was incomplete, evidenced by beaded appearance of the immature myelin sheath and the endoneurium was not apparently increased (Fig.6). In some fascicles, most of the nerve fibers were regenerating (Fig.7). Small (Fig.7) and Large (Fig.6) blood vessels were observed in the endoneurium.

After ten days of deltamethrin treatment cessation (group 5), few groups of regenerating small nerve fibers were observed (Figs.8, 9) some of them showed onion bulb regeneration (Fig.9). However, degenerated nerve fibers were still observed in some fascicles (Figs.8, 9). The endoneurium was abundant in some fascicles accompanied by decreased number of myelinated nerve fibers with marked cellular infiltration in the perineurium (Fig.8). Nonmyelinated nerve fibers appeared normal (Fig.9).

The sections of (group 6 ) demonstrated that most of nerve fibers were either regenerating or normal (Figs.10, 11) with few degenerated nerve fibers (Fig. 10). The nonmyelinated nerve fibers appeared normal (Fig.10). Large blood vessels were observed in the endoneurium (Figs.10, 11). 


\section{Electron Microscopy}

Electron microscopic study of groups 1 and2 revealed the normal structure of the nerve fibers. The myelin sheath was compact and lineated while the axoplasm contained mitochondria and numerous neurofibrils. Schwann cells appeared surrounding the myelin sheath (Fig.12). The fibers of endoneurium could be observed (Figs.12,13). The nonmyelinated nerve fibers appeared in groups; their axoplasm contained mitochondria and neurofibrils (Fig.13).

Deltamethrin administration (group 3) resulted in degeneration of numerous myelinated nerve fibers. Some nerve fibers showed moderate degeneration in the form of partial disruption of the myelin sheath which became absent in some areas, incompact or homogenous (loss of its linear pattern) in other areas. There was intraaxonal edema (Fig. 14). Many fibers were severely degenerated, their myelin sheath was completely fragmented and their fragments replaced the markedly degenerated axons (Fig.15), while some fibers were completely degenerated with ruptured myelin sheath (Fig.16), however, the nonmyelinated nerve fibers appeared non-affected (Fig.14).

The degenerative effect of deltamethrin became less with concomitant administration of ascorbic acid (group 4). Some fibers showed mild degree of degeneration affecting the myelin sheath only (Figs.17-20), others were moderately degenerated affecting axoplasm and myelin sheath (Fig.18), while few fibers were severely degenerated (Figs.18, 19). The nonmyelinated nerve fibers appeared normal (Fig.20).

Examination of sections of (group5) revealed partial improvement compared to group 3. Few nerve fibers were severely degenerated (Figs.21, 22), while most of the degenerated nerve fibers were mildly affected (Figs.21-23) with appearance of small regenerating nerve fibers (Fig 22). The nonmyelinated nerve fibers were non-affected (Fig.23).

There was marked improvement of the nerve fibers in (group 6) compared to other experimental groups. The degenerated nerve fibers were few and showed mild degree of degeneration affecting only the myelin sheath (Figs.24, 25), many regenerating myelinated nerve fibers were observed (Figs.26, 27), and some of them were encompassed by Schwann cells (Figs.26, 27). The nonmyelinated nerve fibers appeared normal (Fig.27). 


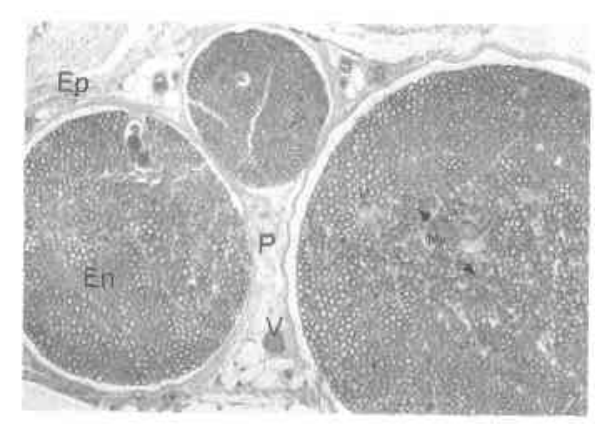

Fig. (1): A photomicrograph of a cross section in the sciatic nerve of rat from control group (1) showing three nerve fascicles surrounded by epineurium (Ep) and perineurium (P) sheathes. The myelin sheathes (My) are surrounded by endoneurium (En). The endoneurium and perineurium contain small blood vessels $(V)$. (Osmic acid; $X$ 40)

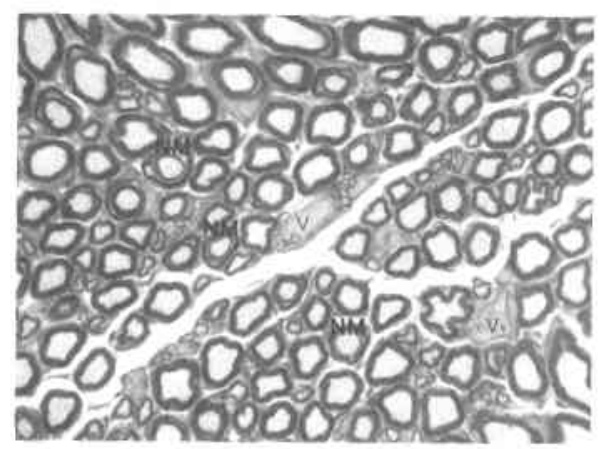

Fig. (3): A photomicrograph of a cross section in sciatic nerve of rat from the control group (1) showing the normal appearance of the nerve fibers with small to large myelinated fibers and some nonmyelinated nerve fibers (NM). Small blood vessels $(V)$ can be seen. (Toluidine blue; $X$ 1000)

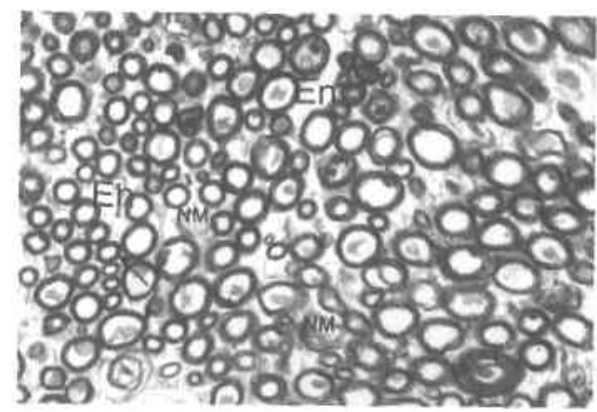

Fig. (2): Higher magnification of figure 1 showing normal appearance of the sciatic nerve, with small to large myelinated axons (arrows) and nonmyelinated nerve fibers (NM) surrounded by endoneurium (En). (Osmic acid; $X$ 200)

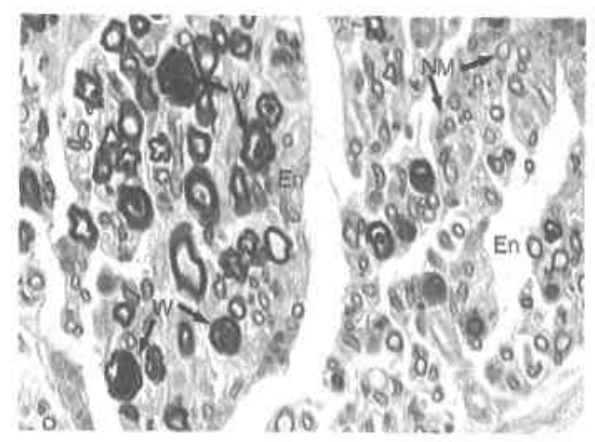

Fig. (4): A photomicrograph of a cross section in sciatic nerve of rat from group (3) showing many nonmyelinated fibers (NM), less number of myelinated fibers many of them show Wallerian degeneration (W) with prominence of connective tissue endoneurium (En). (Osmic acid; X200) 


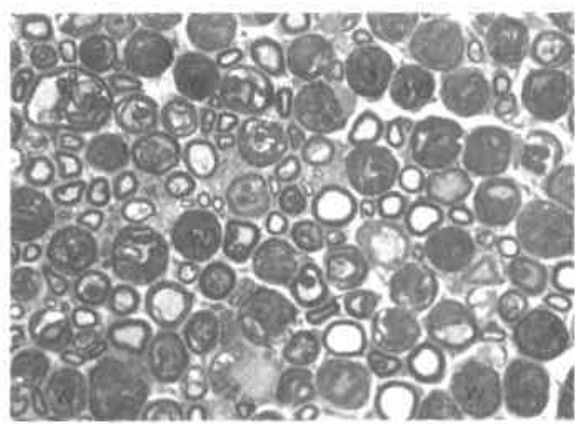

Fig. (5): A photomicrograph of a cross section in sciatic nerve of rat from group (3) showing that most of nerve fibers are swollen and showing Wallerian degeneration (W). (Toluidine blue; $X$ 1000)

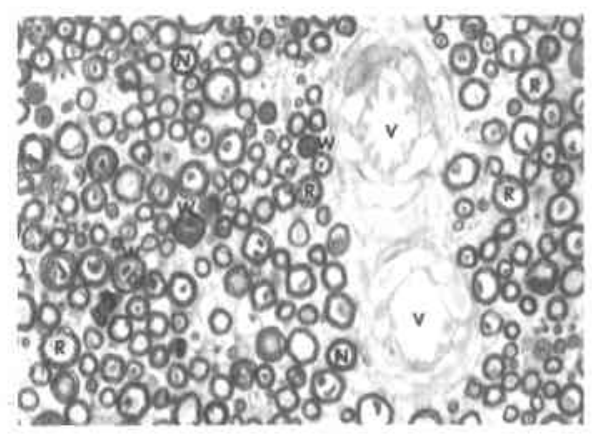

Fig. (6): A photomicrograph of a cross section in sciatic nerve of rat from group (4) showing many regenerated axons with beaded myelin sheath of various diameter (R) and some axons show Wallerian degeneration (W). Two large blood vessels $(V)$ can be seen in the endoneurium. Some normal myelinated nerve fibers $(\mathrm{N})$ can be observed. (Osmic acid; X200)

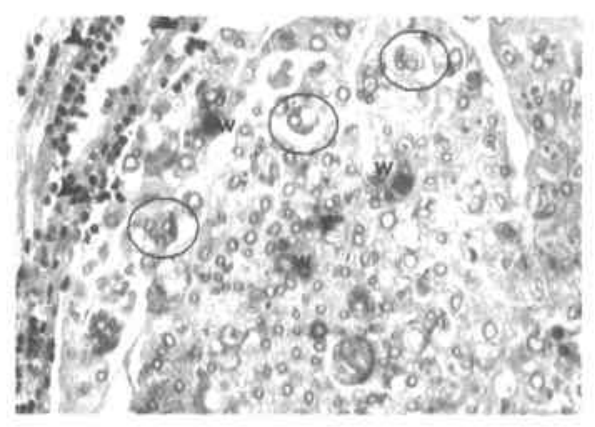

Fig. (8): A photomicrograph of a cross section in sciatic nerve of rat from group (5) showing groups of regenerating nerve fibers (circles), few axons with Wallerian degeneration (W) and marked cellular infiltration in perineurium (arrows head). The endoneurium is abundant with less number of myelinated nerve fibers. (Osmic acid; X200) 


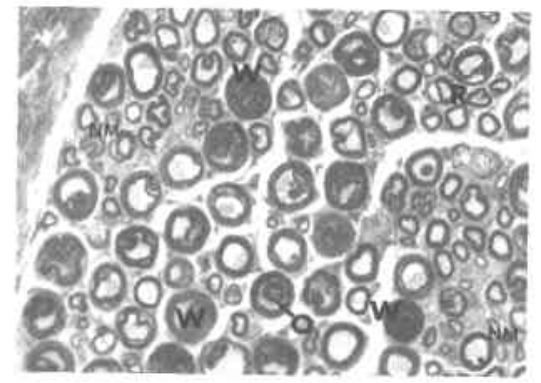

Fig. (9): A photomicrograph of a cross section in sciatic nerve of rat from group (5), showing many myelinated fibers with Wallerian degeneration $(M)$, some regenerating $(R)$ fibers. Onion bulb regeneration (O) can be seen. The nonmyelinated nerve fibers (NM) appear normal. (Toluidine blue; $X$ 1000)

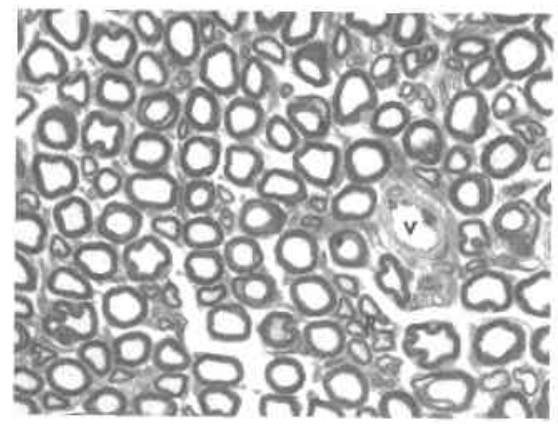

Fig. (11): A photomicrograph of a transverse section in sciatic nerve of rat from group (6) showing that most of the nerve fibers are normal .Some regenerating nerve fibers $(R)$ can be observed. A large blood vessel $(V)$ can be seen. (Toluidine blue; X1000)

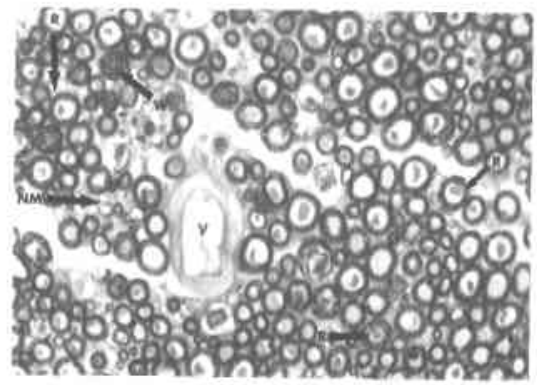

Fig. (10): A photomicrograph of a cross section in sciatic nerve of rat from group (6) showing few myelinated fibers with Wallerian degeneration (W). Most of nerve fibers are regenerating with beaded myelin sheath (R). A large blood vessel ( $V$ ) is seen. The nonmyelinated nerve fibers (NM) appear normal. (Osmic acid; X200)

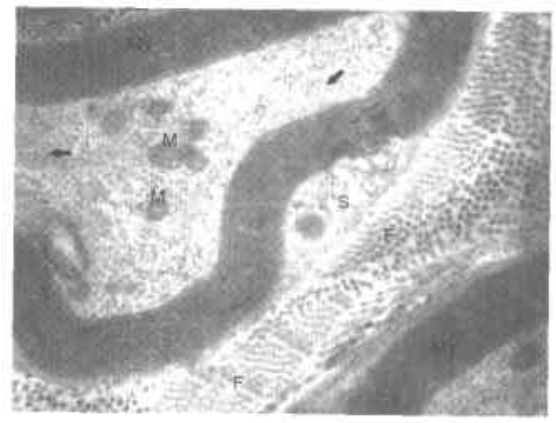

Fig. (12): An electronmicrograph of a transverse section of a myelinated nerve fiber in the sciatic nerve of rat from control group(1) showing that the axoplasm contains mitochondria (M) and numerous neurofibrils (arrow). The myelin sheath (MY) is compact and lineated. A part of Schwann cell (S), which is surrounding the myelin sheath, can be seen. The fibers of endoneurium (F) are also observed both in transverse and longitudinal sections. A part of another nerve can be observed. $(X \mathbf{8 , 0 0 0 )}$ 


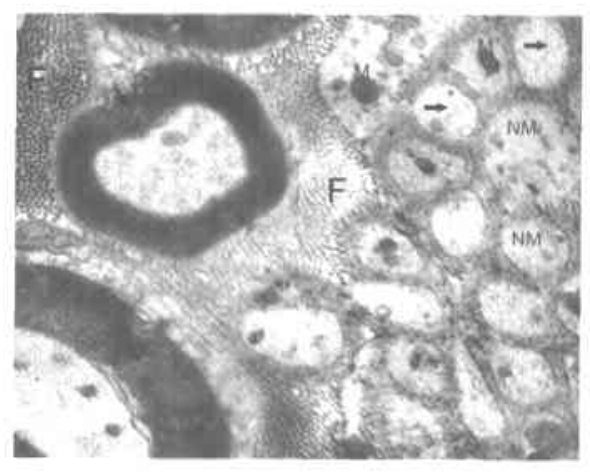

Fig. (13): An electronmicrograph of a transverse section of the sciatic nerve of rat from control group (1) showing a group of nonmyelinated nerve fibers (NM), their axoplasm contains mitochondria (M) and numerous neurofibrils (arrow). Myelinated nerve fiber of small caliber and a part of a larger one are seen. The fibers of endoneurium $(F)$ are observed. $(X \mathbf{6 , 0 0 0})$

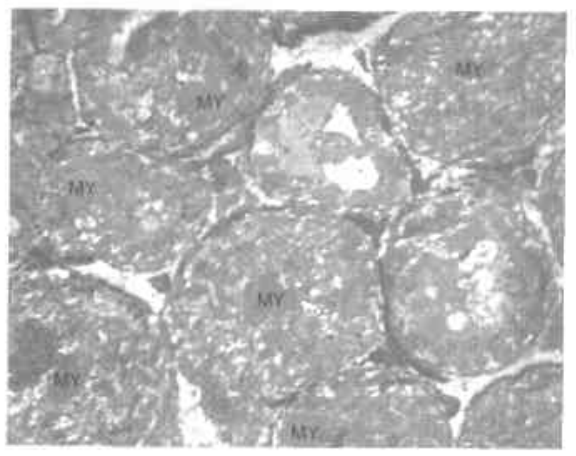

Fig. (15): An electronmicrograph of a transverse section of the sciatic nerve of rat from group (3) showing a group of severely degenerated myelinated nerve fibers. The myelin sheath is absent around the nerve fibers and its fragments (MY) replace the degenerated axons. (X 3,000)

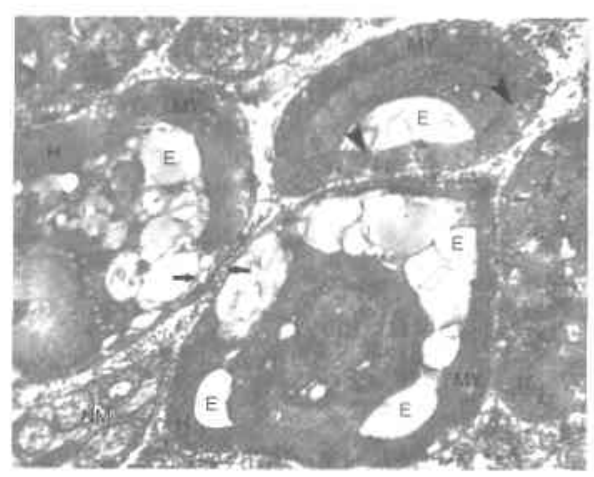

Fig. (14): An electronmicrograph of a transverse section of the sciatic nerve of rat from group (3) showing three myelinated nerve fibers with moderate degeneration : the myelin sheath (MY) is not complete (arrow), incompact (arrow head) or homogenous $(H)$ as no myelin lines are seen, intra-axonal edema $(E)$ is observed. The nonmyelinated fibers (NM) appear nonaffected. $(X 8,000)$

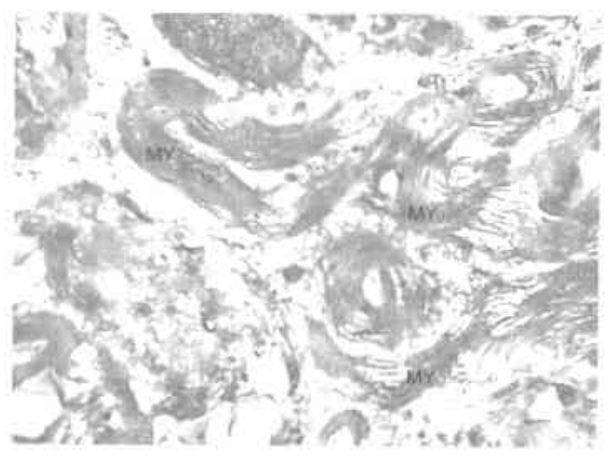

Fig. (16): An electronmicrograph of a transverse section of the sciatic nerve of rat from group (3) showing myelinated nerve fibers in complete degeneration. Their myelin sheath (MY) is fragmented and ruptured.

$(\times 8,000)$ 


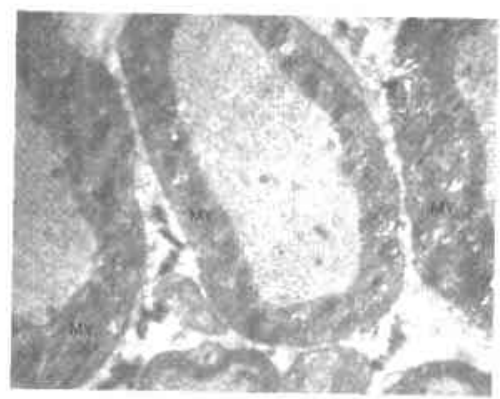

Fig. (17): An electronmicrograph of a transverse section of the sciatic nerve of rat from group (4), showing three mildly degenerated nerve fibers. The axoplasm is intact, while the myelin sheath (MY) shows partial degeneration: incompact and losses its lineated pattern. $(X 6,000)$

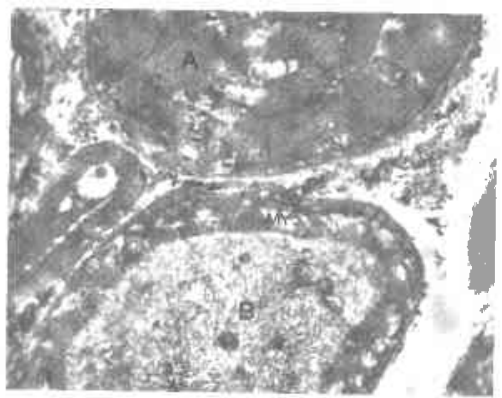

Fig.(19): An electronmicrograph of a transverse section of the sciatic nerve of rat from group (4) showing two myelinated nerve fibers. The nerve fiber $(A)$ shows severe degeneration both in axoplasm and myelin sheath. The nerve fiber (B) is mildly degenerated where the axoplasm is normal and the myelin sheath (MY) is partially degenerated (incompact). (X 8,000)

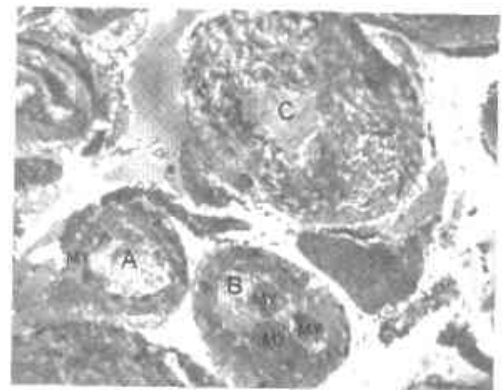

Fig.(18): An electronmicrograph of a transverse section of the sciatic nerve of rat from group (4) showing a nerve fiber (A) with a normal axoplasm and homogenous myelin sheath (MY), a moderately degenerated nerve fiber $(B)$ with degenerated axoplasm and fragments of myelin sheath inside (MY). The nerve fiber (C) shows severe degeneration both in axoplasm and myelin sheath. $(X 4,000)$

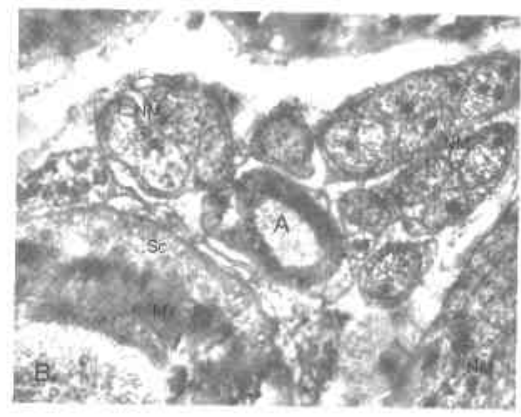

Fig. (20): An electronmicrograph of a transverse section of the sciatic nerve of rat from group (4) showing a mildly degenerated myelinated nerve fiber (A). A part of larger nerve fiber (B) with affected myelin sheath (is incompact and losses its lineated pattern) and a part of its Schwann cell (Sc) with normal cytoplasm is seen. Groups of normal non myelinated nerve fibers (NM) can be observed. (X 10,000) 


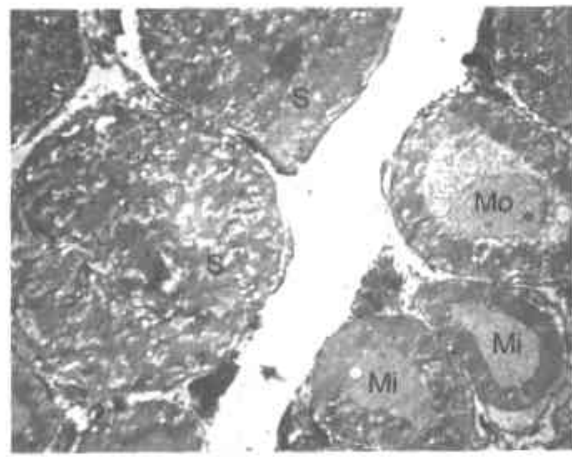

Fig. (21): An electronmicrograph of a transverse section of the sciatic nerve of rat from group (5) showing two severely degenerated nerve fibers ( $S$ ), one moderately degenerated (MO) and two mildly degenerated ones (Mi). (X 3,000)

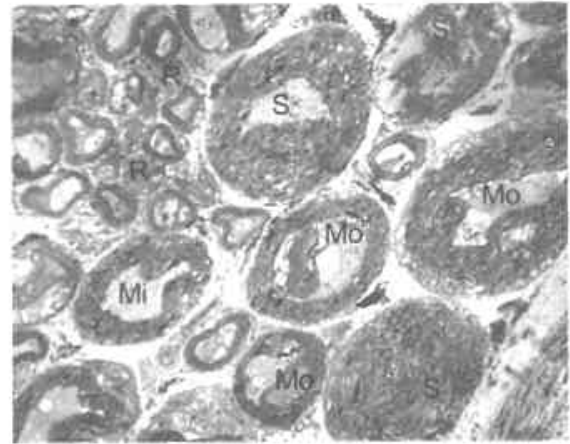

Fig. (22): An electronmicrograph of a transverse section of the sciatic nerve of rat from group (5) showing three severely degenerated myelinated nerve fibers (S), three moderately degenerated nerve fibers $(\mathrm{MO})$ and a mildly degenerated one (Mi). A group of regenerating nerve fibers of small caliber (R) can be seen. $(X 2,000)$

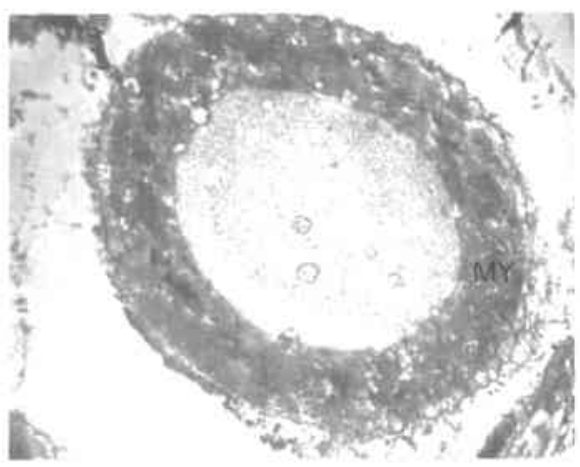

Fig. (24): An electronmicrograph of a transverse section of the sciatic nerve of rat from group (6) showing a mildly degenerated nerve fiber with normal axoplasm and abnormal myelin sheath (MY) which is incompact and losses its lineated appearance. $(X 6,000)$ 


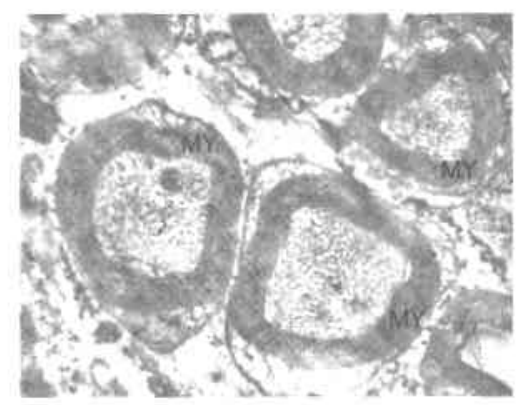

Fig. (25): An electronmicrograph of a transverse section of the sciatic nerve of rat from group (6) showing three myelinated nerve fibers with ultra structurally normal axonal contents and partly degenerated myelin sheath (My), which is incompact and losses its lineated pattem. (X 10,000)

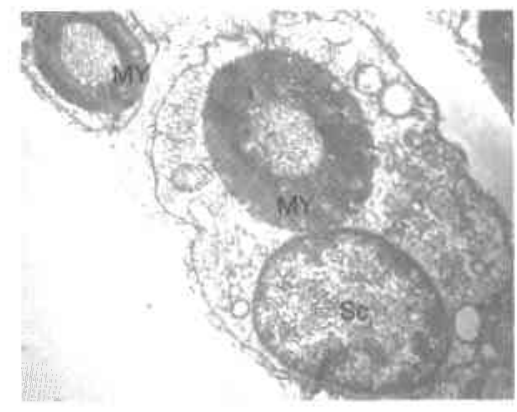

Fig. (26): An electronmicrograph of a transverse section of the sciatic nerve of rat from group (6) showing Schwann cell (Sc) with prominent nucleus and well-developed cytoplasm encompassing a regenerating myelinated nerve fiber with incompletely regenerated myelin sheath (My). Another small regenerating fiber can be observed. $(X 6,000)$

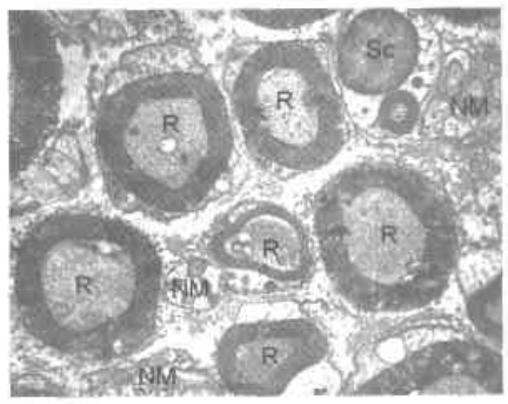

Fig. (27): An electronmicrograph of a transverse section of the sciatic nerve of rat from group (6) showing a group of regenerating myelinated nerve fibers $(R)$. One of them is of small caliber and is encompassed by Schwann cell (Sc). Groups of normal nonmyelinated nerve fibers (NM) can be seen. $(X 4,000)$ 


\section{DISCUSSION}

The clinical manifestations, after deltamethrin administration, observed in the present study may be attributed to the central nervous system toxicity. This is in agreement with Husain et al. (1996) who demonstrated that the disturbed neurological manifestations were due to disturbance in the chemical transmitters in the brain. Also, Grosse et al. (2002) explained these manifestations by loss of fine-tuning of neuronal activity. Moreover, Hossain et al. (2004) reported that deltamethrin increased level of acetyl choline in the hippocampus which resulted in disturbed neurological behaviour.

After deltamethrin administration, light microscopic examination revealed that there was marked degeneration of myelinated nerve fibers in some fascicles. In other fascicles there was complete degeneration of many nerve fibers evidenced by the increase in amount of endoneurium together with decrease of the number of myelinated nerve fibers. Electron microscopic examination demonstrated different degrees of degeneration, from moderate to complete, affecting both axoplasm and myelin sheath of myelinated nerve fibers, while there was no obvious affection of the nonmyelinated nerve fibers. These findings are consistent with those obtained by Theophilidis et al. (1997) and Calore et al. (2000). On the other hand, the results of the present work contradicted those of Dick et al. (1984) who found no peripheral nerve affection in rats fed for long periods with permethrin. However, they had used permethrin (type I pyretheroids) which lacks the a-cyano group present in deltamethrin. This is supported by the findings of Soderlund et al. (2002) who reported that type II pyretheroids, containing the a-cyano group, affected both central and peripheral nervous systems, much more than type I did. On the other hand, Moretto (1991) and Lessenger (1992) reported that there was no peripheral nerve affection in workers spraying pyretheroids apart from cutaneous parasthesia and abnormal facial sensations. The difference of their results from that of the present work may be attributed to different doses to which the mammals were exposed.

Deltamethrin neurotoxicity may be attributed to many causes. Wu and Liu (2000) found that deltamethrin caused DNA fragmentation of brain cells resulting in their degeneration, while Wu et al. (2000) and Wu et al. (2003) referred its neurotoxicity to marked increase of P53 and Bax genes which enhanced apoptosis of brain cells. In addition, Martinez-Larranaga et al. (2003) demonstrated 5-HT loss in the brain which resulted in marked decrease in brain neurotransmission. Also, Aziz et al. (2001) reported that deltamethrin competitively blocked the neuronal voltage-dependent channuis. On the other hand, Braguini et al. (2004) demonstrated that deltamethrin blocked $\mathrm{Na}+$ channels of the mitochondrial membranes resulting in their degeneration. Accordingly, peripheral nerve degeneration could be 
explained by the lack of signals received by some AHCs which may cause degeneration of their neurones. Also, it may be a result of sodium channel blockage of axonal and mitochondrial membranes, resulting in their degeneration.

in the present study, the concomitant administration of ascorbic acid with deltamethrin had minimized the toxic effect of deltamethrin on nerve fibers. Some fibers showed Wallerian degeneration, others were regenerating, while others showed normal structure. These findings were in agreement with Kaviraj (2003) who found that dietary supplement of ascorbic acid reduced greatly the neuronal stress observed in fresh water catfish after deltamethrin administration.

Theron and Andersen (1985) suggested that the protective role of ascorbic acid could be due to its strong antioxidant properties. They found that ascorbic acid neutralized the oxidants generated from neutrophil myeloperoxidase halide system, released by stimulated neutrophils in different inflammatory conditions; thus suppressed the inactivation of antiproteases mediated by these oxidants. Also, Slater (1984) reported that ascorbic acid was contributed to the regeneration of the cell membranes. Moreover, Frei and Loginove (1998) indicated that ascorbate was capable of complete protection of lipids against peroxidative damage and spared $\alpha$-tocopherol which is a great membrane stabilizer.

The regeneration of nerve fibers, demonstrated in the present work, was markedly enhanced with concomitant administration of ascorbic acid with deltamethrin. It was observed that the endoneurium was preserved. It was found by Ross (2003) that the nerve fiber regeneration was dependent on the presence of healthy endoneuronal tubes through which sprouts of the regenerating axons grew. The increased blood supply observed in the present study with vitamin $\mathrm{C}$ administration may promote the process of regeneration which is in accordance with Islamov et al. (2002), who reported that adequate blood supply was important for nerve regeneration. Moreover, the severity of degeneration was markedly decreased with ascorbic acid administration which might accelerate the regeneration process. This proposal is based on the findings of Tseng et al. (2003), who demonstrated that the regeneration of nerve fibers depended on the severity of nerve injury.

With ascorbic acid administration in the present study, many Schwann cells were observed encompassing the regenerating nerve fibers. This was explained by Ross (2003), who reported that remyelination of regenerated axons after injury took place in a manner similar to that for developing nerve fibers. It involved alignment of Schwann cells and encircling of the axons to form multilamellated sheaths that gave the axons onion bulb appearance. However, this onion bulb was described by Subang and 
Richardson (2001) to be encountered in acquired neuropathy.

The nonaffection of nonmyelinated nerve fibers, throughout the present work, may be explained by the fact reported by Soderlund et al. (2002) that deltamethrin was concentrated more in body fat. Accordingly, it was directed to the myelin sheath, which is lipid in nature, thus the nonmyelinated nerve fibers had escaped the toxic effect of deltamethrin.

It could be concluded that deltamethrin administration resulted in marked degeneration in peripheral nerves which became less marked after deltamethrin cessation. Vitamin $\mathrm{C}$ administration greatly minimized the toxic effect of deltamethrin and enhanced the process of regeneration. So, it is recommended not to use deltamethrin in agriculture and for insect control as much as possible. It is also advisable for pyretheroid sprayers to wear protective clothes and masks and to be supplemented with high doses of vitamin $\mathrm{C}$.

\section{SUMMARY}

The aim of the present work was to study the histological changes of the sciatic nerve of rats intoxicated with deltamethrin. It was also aimed to detect the possible protective effect of ascorbic acid when given concomitantly with deltamethrin.

This study was carried out on 80 adult male albino rats. They were divided into six groups: group 1 (normal control group), 20 rats, received no medication, group 2 (sham control group), 20 rats, was divided into two equal subgroups: subgroup $2 a$ received ascorbic acid and subgroup $2 b$ received corn oil for three successive days, group 3 (Deltamethrin treated group), group 4 (Ascorbic acid and Deltamethrin treated group), group 5 (Deltamethrin withdrawal group), group 6 (Ascorbic acid and Deltamethrin withdrawal group), each of the treated groups(3-6) consisted of ten rats. Deltamethrin was given for three successive days, while ascorbic acid was given for six successive days (started three days before deltamethrin administration). The animals of groups $3 \& 4$ were sacrificed on the second day after the third deltamethrin dose, while those of groups $5 \& 6$ were sacrificed ten days after deltamethrin cessation. Half rats of the control groups were used as a control for groups $3 \& 4$, while the other half were used as a control for groups 5\&6. Sciatic nerve of each rat was obtained and subjected to light microscopic examination, using osmic acid and toluidine blue stains, and electron microscopic examination.

Light microscopic examination revealed that after deltamethrin administration, there was obvious increase in C.T. endoneurium with marked decrease in myelinated nerve fibers, most of them showed Wallerian degeneration. Administration of ascorbic acid with deltamethrin had minimized the degenerative effect of deltamethrin on nerve fibers. After ten days of del- 
tamethrin cessation, few groups of regenerating small nerve fibers were observed however; many degenerated nerve fibers were still observed. Ten days after deltamethrin and ascorbic acid cessation most of the nerve fibers were either regenerating or normal. Electron microscopic study revealed that deltamethrin administration resulted in degeneration of numerous myelinated nerve fibers. The degenerative effect of deltamethrin was minimized with concomitant administration of ascorbic acid. Ten days after deltamethrin cessation, there was partial improvement with appearance of regenerating nerve fibers. This improvement was markedly increased and regeneration was greatly enhanced with concomitant ascorbic acid administration. Both light and electron microscopy revealed that the nonmyelinated nerve fibers were not affected.

It could be concluded that deltamethrin administration resulted in marked degeneration in peripheral nerves which became less marked after deltamethrin cessation. Also, ascorbic acid administration greatly minimized the toxic effect of deltamethrin and enhanced the process of regeneration.

\section{REFERENCES}

1. Aziz, M.H.; Agrawal, A.K.; Adhami, V.M.; Shukla, Y. and Seth, P.K. (2001): Neurodevelopmental consequences of gestational exposure (GD14-GD20) to low dose deltamethrin in rats. Neurosci. Lett., 300: 161165.

2. Bendich, A.; Machlin, L.L. and Scandurra, O. (1986): The anti oxidant role of vit. C adv. free radical. Biol. Med., 2:419 -435 .

3. Braguini, W.L.; Cadena, S.M.; Carnieri, E.G.; Rocha, M.E. and Oliveira, M.B. (2004): Effects of deltamethrin on functions of rat liver mitochondria and on native and synthetic model membranes. Toxicol. Letters, 152:191-202.

4. Calore, E.E.; Cavaliere, M.j.; Puga, F.R.; Calore, N.M.; Ruckert, A.; Dias, S. and Santos, R. (2000): Histologic peripheral nerve changes in rats induced by deltamethrin. Ecotoxicol. Environ. Saf., $47: 82-86$.

5. Cavaliere, M. J.; Maeda, M.Y.S.; Shih, L.W.S. and Puga, F.R. (1990): Changes in myelinated nerve fibers in skeletal muscle of rats exposed to high doses of permethrin. Ecotoxicol. Environ. Saf., 3: 139-145.

6. Chen, S.; Hsieh, C.; Lin, G.; Tsai, C.; Chen, T. and Yao, C.(2001): Effects on percutaneous electrical stimulation on peripheral nerve regeneration using silicone rubber chambers. J. Biomed. Mater. Res., 57:541549 . 
7. Dick, P. J.; Shimono, M.; Schoening, G. P.; Lais, A. C.; Oviatt, K. F., and Sparks, M. F. (1984): The evaluation of a new synthetic pyrethroid pesticide (permethrin) for neurotoxicity. J. Environ. Pathol. Toxicol. Oncol., 5: $109-117$.

8. Ecobichon, D. J. (1995): Toxic effects of pesticides; In Casarett and Doull's toxicology: The Basic Science of Poisons. $5^{\text {th }}$ ed., McGraw-Hill, New York, 643-690.

9. Frei, R. and Loginove, V. E. (1998): Vitamin C as an antioxidant. Clin. Chem., 44:214-219.

10. Grosse, G.; Thiele, T.; Heuckendorf, E.; Schopp,E.; Merder, S; Pickert,G. and Ahnert-Hilger, G.(2002): Deltamethrin differentially affects neuronal subtypes in hippocampal primary culture. Neuroscience, 112 (1):233-241.

11. Hossain, M.M.; Suzuki,T; Sato, I.; Takewaki, T.; Suzuki, K. and Kobayashi, H. (2004): The modulatory effect of pyretheroids on acetylcholine release in the hippocampus of freely moving rats. Neurotoxicity, 25(5):825833.

12. Husain, R.; Husain, R.; Adhami, V. M. and Seth, P. K. (1996): Behavioral, neurochemical and neuromorphological effects of deltamethrin in adult rats. J. Toxicol. Environ. Health, 48: 515-526.

13. Husain, R.; Malaviya, M.; Seth, P. K. and Husain, R. (1994): Effect of deltamethrin on regional brain polyamines and behaviour in young rats. Pharmacol. Toxicol., 74: 211-215.

14. Islamov, R.; Hendricks, A.; Jones, J.; Lyall, I.; Spanier, S. and Murashov, K. (2002): 17 $\beta$-Estradiol stimulates regeneration of sciatic nerve in female mice. Brain Res., 943:283-290.

15. Jha, P.; Flather, M. and Sysuf, S. (1995): The anti oxidant vitamins and cardiovascular disease. Ann. Inter. Med., 123: 360 -372.

16. Johnson, P. (1997): Textbook of Neuropathology: "Peripheral Nerve". Eds. Davis, R. and Robertson, D., USA, 1233-1260.

17. Joy, R. M. (1994): Pyrethrins and pyrethroid insecticides: In Pesticides and Neurological Diseases. $2^{\text {nd }}$ ed., (D. J. Ecobichon and R. M. Joy, Eds.), CRC Press, Boca Raton, USA, FL., 291-312.

18. Kaviraj, A. (2003): Ascorbic acid supplementation of diet for reduction of deltamethrin induced stress in freshwater catfish Clarias gariepinus. Chemosphere, 53(8): 883-888. 
19. Lessenger, J. E. (1992): Five office workers inadvertently exposed to cypermethrin. J. Toxicol. Environ. Health, 35: 261-267.

20. Mackinnon, S.E.; Dellon, A.L. and Hunter, D.A. (1985): Histologic assessment of nerve regeneration in the rat. Plast. Reconst. Surg., 75:384388.

21. Martinez-Larranaga, M.R.; Anadon, A.; Martinez, M.A.; Castellano, V.J. and Diaz, M.J. (2003): 5-HT loss in rat brain by type II pyrethroid insecticides. Toxicol. Ind. Health, 19(7-10): 147-155.

22. Moretto, A. (1991): Indoor spraying with the pyrethroid insecticide lambda-cyalothrin: Effects on spraymen and inhabitants of sprayed houses. Bull. WHO, 69: 591-594.

23. Moya-Quiles, M.R.; Munoz-Delgado, E. and Vidal, C.J. (1996): The pyrethroid insecticide deltamethrin modifies the thermotropic properties and lipid packing order of model membrane. Chem. Phys. Lipids, 83:61-69.

24. Ross, M.(2003): Histology; A Textbook and Atlas with Cell and molecular Biology. $4^{\text {th }}$ ed., Williams and Wilkins, Lippincot , 293-315.

25. Slater, T.F. (1984): Free radical mechanisms in tissue injury. Biochem. J., 222: 1-15.

26. Soderlund, D.M.; Clark, J.M.; Sheets, L.P.; Mullin, L.S.; Piccirillo, V.J.; Sargent, D.; Stevens, J.T. and Weiner, M.L. (2002): Mechanisms of pyrethroid neurotoxicity : Implications for cumulative risk assessment. Toxicol., $171: 53-59$.

27. Subang, M. C. and Richardson, P. M. (2001): Influence of injury and cytokines on synthesis of monocyte chemoattractant protein-1 $\mathrm{m}$ RNA in peripheral nerve tissue. Eur. J. Neurosci., 13: 521-528.

28. Theophilidis, G.; Benaki, M. and Papadopoulou-Mourkidou, E. (1997) : Neurotoxic action of six pyrethroid insecticides on the isolated sciatic nerve of a frog (Rana Ridibunda). Comp. Biochem. Physiol. C Pharmacol. Toxicol. Endocrinol., 118(1) : 97-103.

29. Theron, A. and Anderson, R. (1985): Investigation of the protective effects of the antioxidants ascorbate, cysteine and dapsone on the phyagocyte medicated in activation of human Alpha-1-protease inhibior. Am. Rev. Respir. Dis., 133: 1049-1051.

30. Tseng, C. Y.; Hu, G.; Amborn, R. T. and Chiu, D. T. (2003): Histologic analysis of Schwann cell migration and peripheral nerve regeneration in the autogenous venous nerve conduit (AVNC). J. Reconstr. Microsurg., 19(5):331-340. 
31. Wu, A. and Liu, Y.(2000): Apoptotic cell death in rat brain following deltamethrin treatment. Neurosci. Lett., 279(2):85-88.

32. Wu, A.; Li,L. and Liu, Y.(2003): Deltamethrin induces apoptotic cell death in cultured cerebral cortical neurons. Toxicol. Appl. Pharmacol., 187 (1): $50-57$.

33. Wu, A.; Ren,T.; Hu,Q. and Liu, Y.(2000): Deltamethrin induces altered expression of P53, Bax and Bel-2 in rat brain. Neurosci. Lett., 284(1-2):2932. 


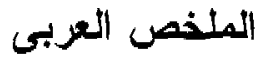

اللدور الوقائى لحمض الأسكورييك (فيتامين ج) فى التسمم العصبى العبى

للالتامثرين على العصب الموركى للفار الابيض

محمد ايهاب الدين مصطقى

قسم التشريح ، كلية الطب ، جامعة القاهرة

استهفف البحث الحالى دراسة التُغيرات الهيستولوجيه للعصب الوركي للفئر ان التى التى

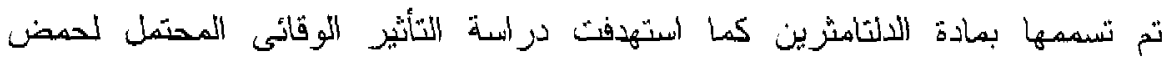
الأسكوربيك عند اعطائه مع الدالتامثرين.

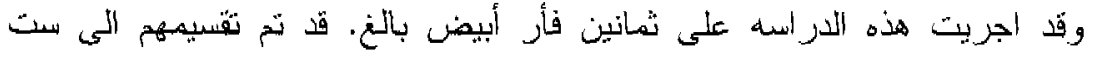

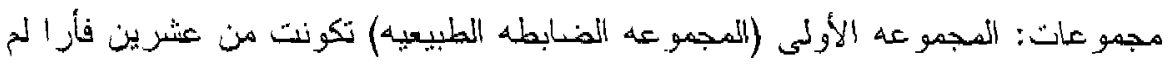

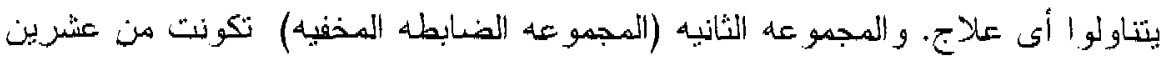

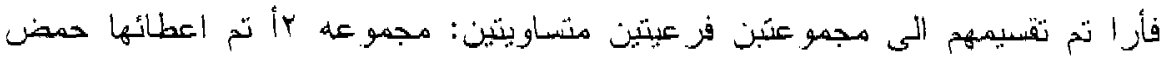

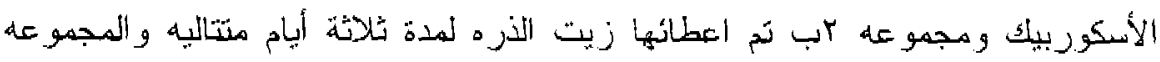

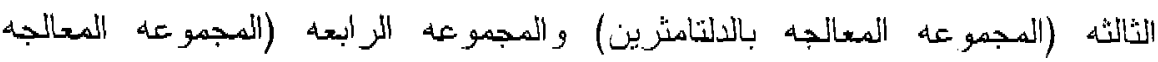

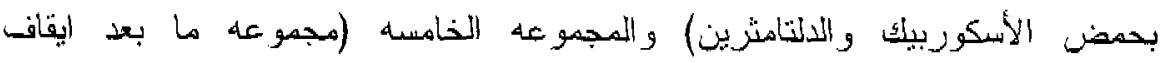

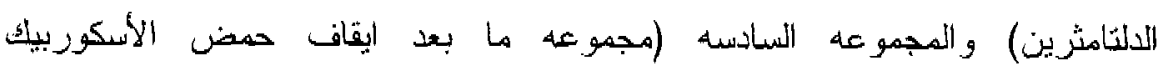

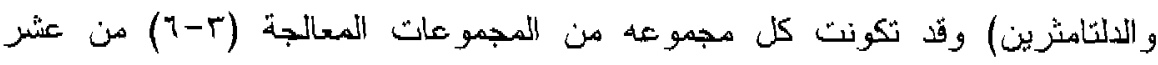

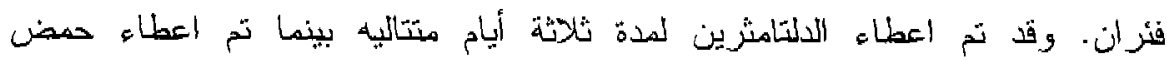

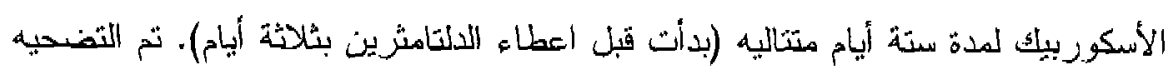

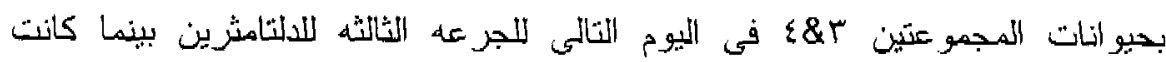

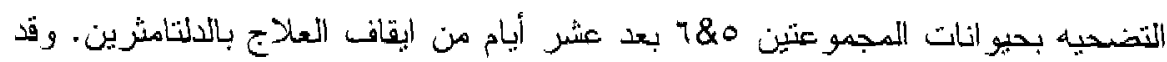

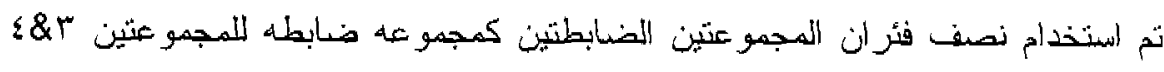

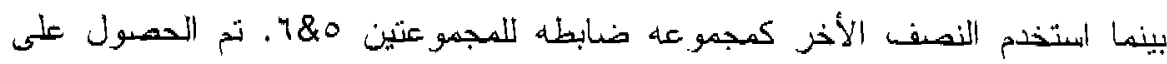
العصب الوركى لكل فأر وتم تعريضه للفحص بالكيكروسكوب الضوئى باستخام 
صبيغات حمضن الأوزميك و التوليودين الأزرق كما تم فحصه بالميكروسكوب الأككترونى.

أظهر الفحص بالميكروسكوب الضوئي بعد اعطاء الالتامثرين انه كانت هناك

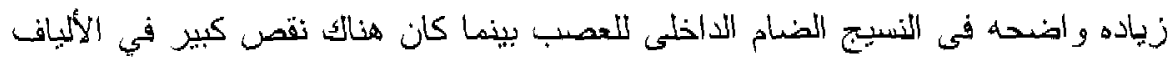

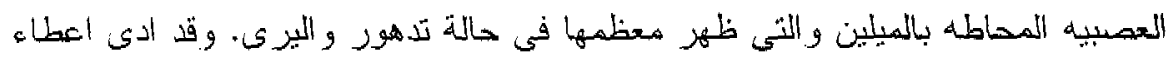

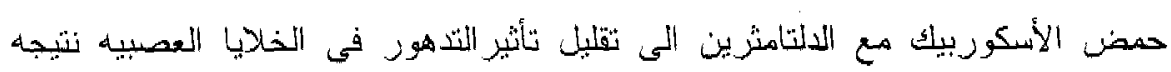

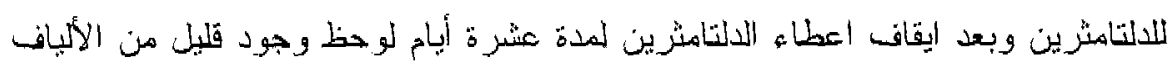

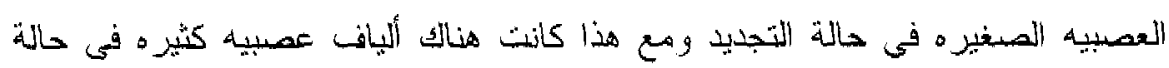

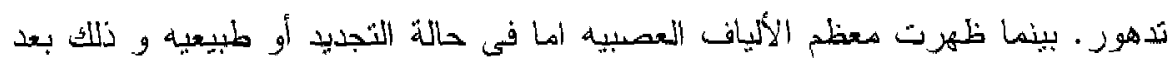

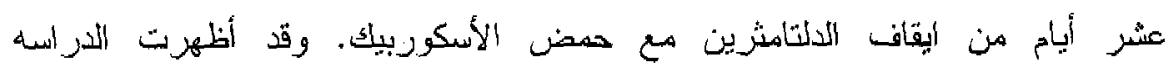

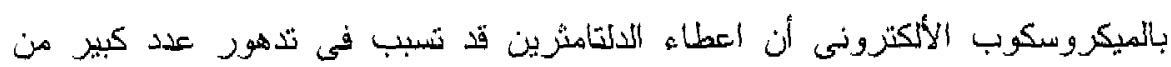

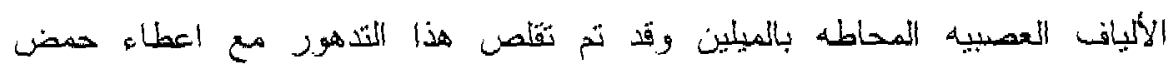

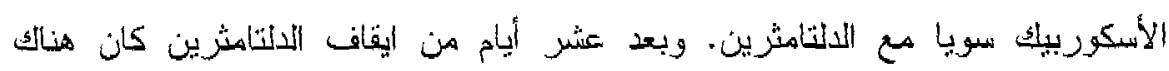

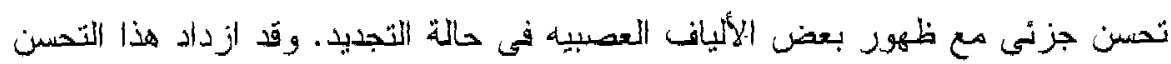

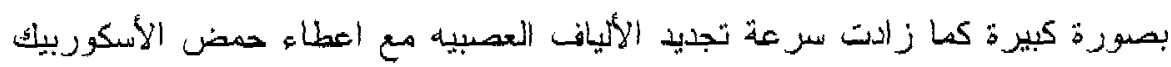

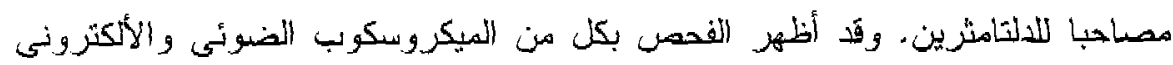

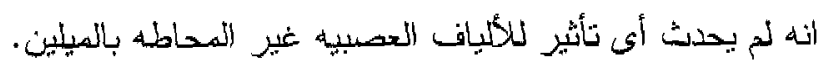

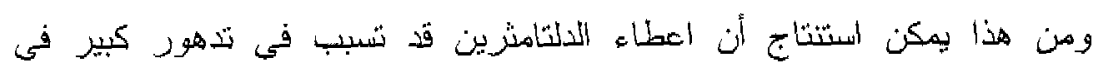

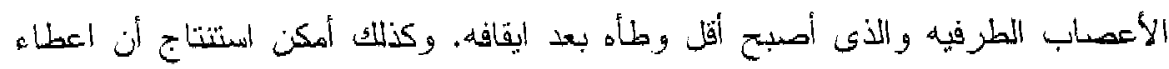

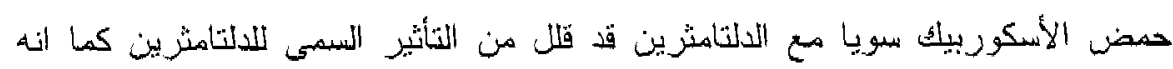
ز اد من سر عنة مملية التجديد.

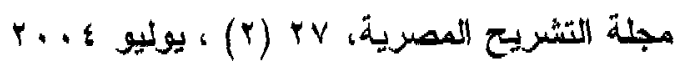

